J. Lake Sci.(湖泊科学), 2009, 21(6): 782-788

http://www.jlakes.org. E-mail: jlakes@niglas.ac.cn

(C)2009 by Journal of Lake Sciences

\title{
微曝气生态浮床净化入湖河口污染河水原位模型实验*
}

\author{
李海英 ${ }^{1,2}$, 冯慕华 ${ }^{1}$, 李 玲 $^{1}$, 柯 凡 $^{1}$, 李文朝 ${ }^{1 * *}$ \\ (1: 中国科学院南京地理与湖泊研究所湖泊与环境国家重点实验室, 南京 210008) \\ (2: 中国科学院研究生院, 北京 100049)
}

摘 要: 针对污染河水黑臭缺氧、 $\mathrm{NH}_{4}{ }^{+}-\mathrm{N}$ 含量高等问题, 研发了一种“漂浮载体悬挂弹性生物膜填料+水生植物并辅以人工微 曝气系统”的微曝气生态浮床系统. 通过原位模型实验, 研究了其在大清河人湖河口对污染河水的净化效果, 当水力负荷为 $1500 \mathrm{~mm} / \mathrm{d}$ 时, 对 $\mathrm{TN}$ 和 $\mathrm{NH}_{4}{ }^{+}-\mathrm{N}$ 的平均去除率分别为 $81.1 \% 、 91.3 \%$, 对 TP 的平均去除率为 $72.7 \%$, 对 $\mathrm{PO}_{4}{ }^{3-}-\mathrm{P}$ 的平均去除率 为 $92.5 \%$, 对有机物亦有较强的去除能力; 处理 $1 \mathrm{~m}^{3}$ 水需要的曝气费用约为 0.007 元. 微曝气生态浮床系统整体运行稳定、去 除效率高、能耗低，适合流水环境，可直接在污染河道和人湖河口区对污染河水进行自流净化.

关键词: 微曝气生态浮床; 污染河水; 模型试验; 净化效果

\section{In-situ model experiment on purification of polluted river water into lake based on micro-aerated ecological floating bed}

\author{
LI Haiying ${ }^{1,2}$, FENG Muhua ${ }^{1}$, LI Ling ${ }^{1}$, KE Fan $^{1} \&$ LI Wenchao ${ }^{1}$ \\ (1: State Key Laboratory of Lake Science and Environment, Nanjing Institute of Geography and Limnology, Chinese Academy of \\ Sciences, Nanjing 210008, P.R.China) \\ (2: Graduate School of the Chinese Academy of Sciences, Beijing 100049, P.R.China)
}

\begin{abstract}
Aiming at the problem of black-odor, oxygen deficiency and ammonia-nitrogen pollution of polluted rivers, a new type of ecological floating bed-micro-aerated ecological floating bed was developed, which combined biofilm packing, floating aquatic macrophyte and auxiliary aeration device. The purification efficiency of the polluted river water was studied by the model experiment in the outlet of Daqing River. The results showed when the hydraulic loading was $1500 \mathrm{~mm} / \mathrm{d}$, the mean removal efficiencies of total nitrogen, ammonia nitrogen, total phosphorus and phosphate were $81.1 \%, 91.3 \%, 72.7 \%$ and $92.5 \%$, respectively. Additionally, the floating bed showed better removal effect on organic matters. The cost of micro-aerated system to treat $1 \mathrm{~m}^{3}$ of polluted river water was only 0.007 Yuan. The micro-aerated ecological floating bed ran steadily, had a high efficiency of pollutants removal and low energy consumption. It was suitable for the environment of flowing water, which could be used in polluted river and estuary.

Keywords: Micro-aerated ecological floating bed; polluted river water; model experiment; removal efficiency
\end{abstract}

生态浮床技术是运用无土栽培技术原理，以浮床作为载体，采用现代农艺和生态工程措施综合集成 的水面无土种植技术. 该技术通过浮床上种植的水生植物对氮、磷等营养物的吸收作用，根系及人工基 质上附着的微生物对污染物的降解作用，达到净化水体，控制水体富营养化和改善景观之目的 ${ }^{[1-2]}$.

人湖河流是湖泊的主要水量来源，也是污染物进人湖泊的主要通道. 由于人口激增和工农业生产的 发展, 大量污染物质排人河流, 使得水体中 $\mathrm{NH}_{4}{ }^{+}-\mathrm{N}$ 等物质含量高, 长期处于黑臭状态, 这进一步加重了 湖泊的污染负荷. 为了改善湖泊水环境, 控制入湖河流污染是削减湖泊污染负荷的重要方面. 利用河道

* 国家高技术研究发展计划项目(863 计划)(2005AA60101004 和 2006AA06Z325)资助. 2008-12-23 收稿; 2009-03-27 收修 改稿. 李海英, 女, 1978 年生, 博士; E-mail: hyli78@163.com.

** 通讯作者; E-mail: wchli@niglas.ac.cn. 
或河口区水面建设生态工程, 过滤净化人湖河水, 是控制湖泊污染的重要途径之一. 目前, 常用的生态 工程措施有河口自然湿地净化系统和规模化养殖漂浮植物. 河口自然湿地净化系统受到环境条件的严格 限制, 由于河道湖岸的人工化、围垦破坏、过度污染、清淤开挖等人为因素和风浪冲刷等自然因素的影 响, 使得许多河口丧失了湿地以及恢复湿地的环境条件. 规模化养殖漂浮植物也是实施水质净化的有效 方式 ${ }^{[3-7]}$, 但漂浮植物只利用表层水体，且受到季节的影响，其净化主体是植物，主要依靠植物的吸收来 去除 $\mathrm{N} 、 \mathrm{P}$ 等营养物, 生物量的限制阻碍了净化效果的进一步提高 ${ }^{[8-9]}$, 较大养殖规模时, 还存在大量植物 残体处置问题 ${ }^{[10]}$. 因此, 为减轻湖泊污染问题, 在污染较重的人湖河流河口区, 研究对污染河水进行原 位净化的技术具有现实意义.

近年来, 组合型新生态浮床的开发与应用越来越被重视 ${ }^{[11-12]}$. 本文提出一种微曝气生态浮床工艺, 采用“漂浮载体悬挂弹性生物膜填料+漂浮植物结构并辅以人工微曝气系统”, 对黑臭缺氧、 $\mathrm{NH}_{4}{ }^{+}-\mathrm{N}$ 污染 严重的重污染河水进行水质净化. 原位模型实验旨在通过对微曝气生态浮床系统在人湖河口区对污染河 水的处理效果进行研究, 为后续工程建设与应用提供基础资料.

\section{1 材料与方法}

\section{1 实验地点}

实验地点位于昆明市滇池大清河河口东侧福 保文化城六口土埂池塘中的 $1^{\#}$ 池塘(图 1). 大清河 是昆明主城区盘龙江以东主要的排洪、排涝、纳污 河道，同时也是金针河分引松华坝出流进入滇池 的行洪河道. 大清河系包括流域上部的金汁河-清 水河和东郊明沟-海明河, 中部的枕槽河、明通河, 下部的大清河等河流(河段). 集水范围为松华坝以 下、盘龙江以东、东干渠和东白沙河以西至滇池人 口的大部分区域. 从松华坝至滇池人口的主河道 长 $29.4 \mathrm{~km}$, 全流域汇水面积为 $48.4 \mathrm{~km}^{2}$. 大清河是 滇池众多人湖河道中的一条典型河道, 经往年监 测数据可知, 其水质长期劣于地表水环境质量标 准 (GB3838-2002) V 类. 和其它人湖河道一样, 大清河水质的好坏直接影响到滇池的水质状况, 因此本研究将大清河口边围怎池塘作为模型实验 地点.

\section{2 实验区布局}

模型实验区(图 2)用柔性围隔在 $1^{*}$ 池塘西北面沿 北岸围出长 $10 \mathrm{~m}$ 、宽 $10 \mathrm{~m}$ 的区域. 其中围隔墙西端 与西池埂封闭, 围隔墙东端接有 $15 \mathrm{~m}$ 长的拦网, 拦 网末端与北池埂封闭, 以防止鱼类干扰. 在西端围 隔段中心位置设置曝气汲水工程装置, 用于提取大 清河水. 曝气汲水装置东侧布设 $10 \mathrm{~m} \times 10 \mathrm{~m}$ 微曝气

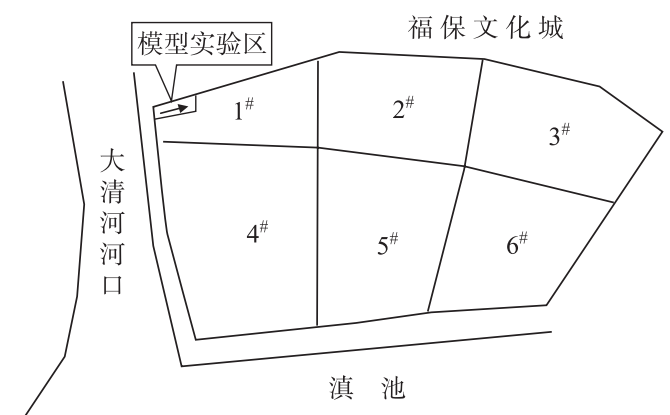

图 1 模型实验区位置

Fig.1 Location of the modelling experiment

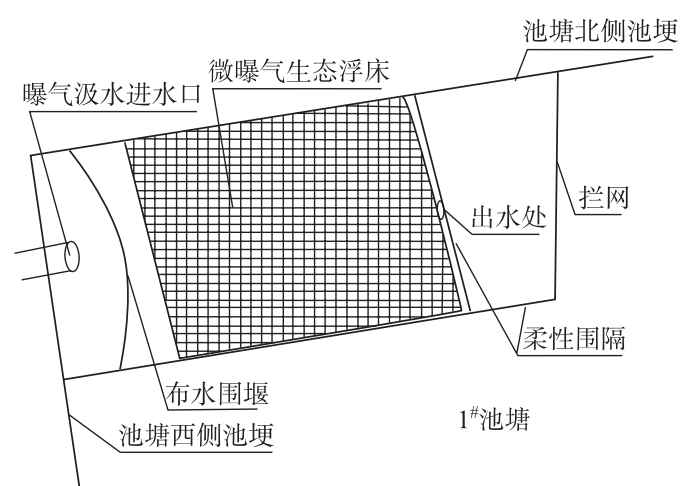

图 2 模型实验区布局设计

Fig.2 Layout of the modelling experiment 生态浮床净化区, 水深 $2 \mathrm{~m}$ 左右.

\section{3 微曝气生态浮床结构设计}

微曝气生态浮床系统采用漂浮载体悬挂弹性生物膜填料+漂浮植物结构(图 3). 在“田”字形框架上面 附着不锈钢丝网格, 四角以塑料浮球承载, 通过其调节浮床在水体中的高度. 在钢丝网格上悬挂 YDT 弹 性立体填料(规格：直径 $15 \mathrm{~cm}$, 长度 $1.5 \mathrm{~m}$ ), 将顶端系于框架网格上, 下端系以沉子以保持伸展. 本实验漂 浮植物选用水芹(Oenanthe javanica), 将水芹幼芽插播在网架上, 自然生长后覆盖载体水面, 遮荫并提供 


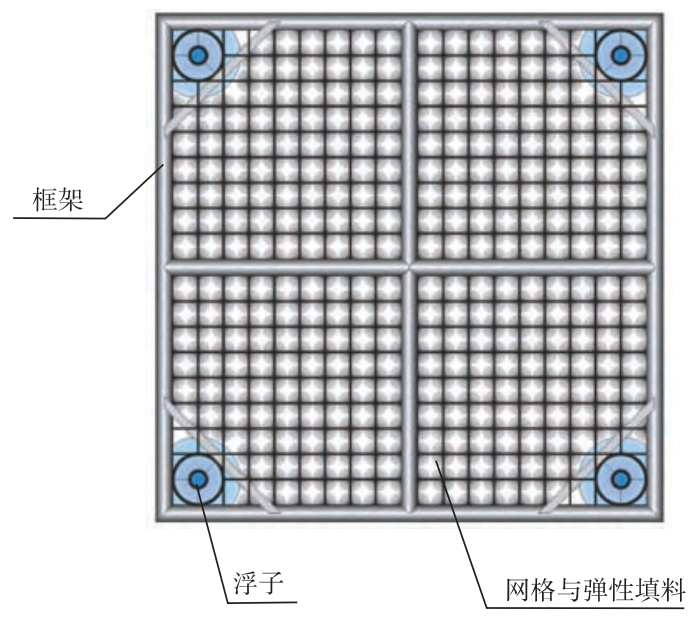

图 3 微曝气生态浮床单元结构图

Fig.3 The structural unit of the aerated ecological floating bed

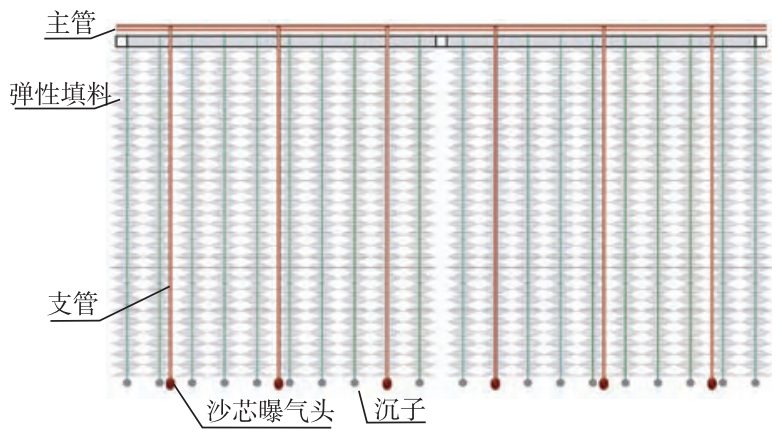

图 4 浮床结构剖面图

Fig.4 The profile of the floating bed
根系净化机制. 生态浮床总面积 $54 \mathrm{~m}^{2}$, 占实 验模型区总面积的 54\%.

曝气系统由主管+支管+沙芯曝气头组成 (图 4); 支管在水中的深度与弹性生物膜填料 的悬挂深度相同，用风机提供动力在净化系 统底部进行连续曝气, 曝气时不会扰动下层 底泥. 本模型实验曝气总量在 $0.41-0.64 \mathrm{~m}^{3} / \mathrm{h}$ 之间，电费按每千瓦时 0.6 元计算，处理 $1 \mathrm{~m}^{3}$ 水需要的曝气费用约为 0.007 元.

\section{4 采样分析}

实验系统于 2006 年 9 月中旬开始运行, 进水流量约 $81 \mathrm{~m}^{3} / \mathrm{d}$, 水力负荷为 $1500 \mathrm{~mm} / \mathrm{d}$, 水力停留时间约为 $2.5 \mathrm{~d}$, 气水比范围为 0.12:1-0.19:1, 系统中 YDT 弹性立体填料采 取自然挂膜方式. 水芹取自云南澄江县马料 河构造湿地, 将其幼芽栽种于漂浮载体框架 内; 2006 年 10 月弹性填料挂膜成功，水芹正 常生长, 并稳定运行到 2007 年 2 月. 模型稳 定运行一段时间后于 2006 年 10 月 16 日至 2007 年 2 月 9 日, 每周两次采集进水口、出 水口水样进行水质分析.

测定项目: 溶解氧(DO)、总氮 $(\mathrm{TN})$ 、氨 氮 $\left(\mathrm{NH}_{4}{ }^{+}-\mathrm{N}\right)$ 、硝氮 $\left(\mathrm{NO}_{3}{ }^{-}-\mathrm{N}\right)$ 、亚硝氮 $\left(\mathrm{NO}_{2}{ }^{-}-\mathrm{N}\right)$ 、 总磷 $(\mathrm{TP})$ 、磷酸盐 $\left(\mathrm{PO}_{4}{ }^{3-}-\mathrm{P}\right) 、 \mathrm{COD}_{\mathrm{Cr}} 、 \mathrm{BOD}_{5}$, 分析方法均采用国家标准方法 ${ }^{[13]}$; 生物膜厚 度采用显微镜测定 ${ }^{[14]}$.

生物膜量测定：在稳定运行的系统中, 取出部分弹性填料放人容器中, 加人一定量 蒸馏水, 反复清洗直至填料上的生物膜被全 部洗脱下为止, 洗脱液用定量滤纸过滤后于 $103-105^{\circ} \mathrm{C}$ 下烘干称其质量, 得生物膜干物质; 再将其放在 $550^{\circ} \mathrm{C}$ 的马福炉中灼烧, 冷却后称其质量, 得到滤后残渣质量, 其与生物膜干物质之差即为挥发性生物膜 质量 ${ }^{[14]}$.

\section{2 结果与分析}

\section{1 进水水质状况}

进水水质指标 $\mathrm{pH} 、 \mathrm{COD}_{\mathrm{Cr}} 、 \mathrm{BOD}_{5} 、 \mathrm{TN} 、 \mathrm{NH}_{4}{ }^{+}-\mathrm{N} 、 \mathrm{NO}_{3}{ }^{-}-\mathrm{N} 、 \mathrm{NO}_{2}{ }^{-}-\mathrm{N} 、 \mathrm{TP} 、 \mathrm{PO}_{4}{ }^{3}-\mathrm{P}$ 分别为 7.79 $\pm 0.12 、$ (121.20 \pm 34.89$) \mathrm{mg} / \mathrm{L} 、(63.86 \pm 17.06) \mathrm{mg} / \mathrm{L} 、(35.00 \pm 11.81) \mathrm{mg} / \mathrm{L} 、(29.67 \pm 7.7) \mathrm{mg} / \mathrm{L} 、(0.14 \pm 0.25) \mathrm{mg} / \mathrm{L} 、(0.02 \pm 0.01)$ $\mathrm{mg} / \mathrm{L} 、(1.17 \pm 0.29) \mathrm{mg} / \mathrm{L} 、(0.49 \pm 0.27) \mathrm{mg} / \mathrm{L}$, 进水的水质波动较大, 主要污染物为有机物和 $\mathrm{NH}_{4}{ }^{+}-\mathrm{N}$, 进水 $\mathrm{NH}_{4}{ }^{+}-\mathrm{N}$ 平均为 $\mathrm{TN}$ 含量的 $85 \%$, 进水 $\mathrm{COD}_{\mathrm{Cr}}$ 和 $\mathrm{BOD}_{5}$ 平均浓度分别为 $121.20 \mathrm{mg} / \mathrm{L} 、 63.86 \mathrm{mg} / \mathrm{L}, \mathrm{BOD}_{5} /$ $\mathrm{COD}_{\mathrm{Cr}}=0.53>0.3$, 说明其可生化性比较好.

由于大清河水长期处于黑臭缺氧状态, $\mathrm{NH}_{4}{ }^{+}-\mathrm{N}$ 含量高, 水力负荷为 $1500 \mathrm{~mm} / \mathrm{d}, \mathrm{COD}_{\mathrm{Cr}}$ 负荷达到 $181.8 \mathrm{~g} /\left(\mathrm{m}^{2} \cdot \mathrm{d}\right), \mathrm{NH}_{4}{ }^{+}-\mathrm{N}$ 负荷为 $44.5 \mathrm{~g} /\left(\mathrm{m}^{2} \cdot \mathrm{d}\right)$, 单纯依靠漂浮植物根系泌氧和大气对水的复氧作用已经无法 满足污染物去除的要求, 必须对生态浮床系统进行适当的人工增氧. 利用微曝气系统可以给系统微生物 处理提供好氧环境 


\section{2 功能生物群的发育}

水芹在系统中正常生长, 2006 年 11 月 15 日收割水芹 1 次, 生物量干重平均为 $594.9 \mathrm{~g} / \mathrm{m}^{2}$. 从第一次 收割到翌年 2 月, 水芹生物量平均为 $401.5 \mathrm{~g} / \mathrm{m}^{2}$, 显著低于第一次收割的生物量, 生长速率为 $8.7 \mathrm{~cm} / 7 \mathrm{~d}$, 较 9-11 月阶段的 $15.4 \mathrm{~cm} / 7 \mathrm{~d}$ 缓慢(表 1), 这主要与当地的气温有关.

表 1 微曝气生态浮床系统内水芹的生长状况

Tab.1 Growing status of Oenanthe javanica in micro-aerated ecological floating bed system

\begin{tabular}{ccccc}
\hline 时间 & $\begin{array}{c}\text { 上部生物量 } \\
\left(\mathrm{g} / \mathrm{m}^{2}\right)\end{array}$ & $\begin{array}{c}\text { 下部生物量 } \\
\left(\mathrm{g} / \mathrm{m}^{2}\right)\end{array}$ & $\begin{array}{c}\text { 总生物量 } \\
\left(\mathrm{g} / \mathrm{m}^{2}\right)\end{array}$ & $\begin{array}{c}\text { 生长速率 } \\
(\mathrm{cm} / 7 \mathrm{~d})\end{array}$ \\
\hline 9-11 月 & $528.1 \pm 46.8$ & $66.8 \pm 3.0$ & $594.9 \pm 35.6$ & $15.4 \pm 2.6$ \\
$11-2$ 月 & $358.3 \pm 25.9$ & $43.2 \pm 8.7$ & $401.5 \pm 18.7$ & $8.7 \pm 3.5$ \\
\hline
\end{tabular}

弹性填料上生物膜的厚度在 $14 \mathrm{~d}$ 左右基本上达到稳定, 此时平均厚度为 $382 \mu \mathrm{m}$ (图 5); 生物膜干物质平 均为 $10.84 \mathrm{~g} / 100 \mathrm{~g}$ 填料, 挥发性生物膜量平均为 $7.17 \mathrm{~g} / 100 \mathrm{~g}$ 填料, 挥发性生物膜量与生物膜干物质 的比值为 0.66 , 活性生物量较高.

\section{3 溶解氧浓度变化}

大清河河口原河水 $\mathrm{DO}$ 浓度平均为 $0.5 \mathrm{mg} / \mathrm{L}$, 而通过曝气汲水的进水方式污染河水刚进人系统 后水体 $\mathrm{DO}$ 平均为 $7.1 \mathrm{mg} / \mathrm{L}$, 出水 $\mathrm{DO}$ 平均为 $4.1 \mathrm{mg} / \mathrm{L}$ (图 6). 可见, 系统 DO 浓度较高. 一方面, 曝气汲水的进水方式显著提高了原污染河水的 $\mathrm{DO}$; 另一方面, 人工布设的微曝气装置强化了系 统的氧化功能, 补充了系统所需要的氧量.

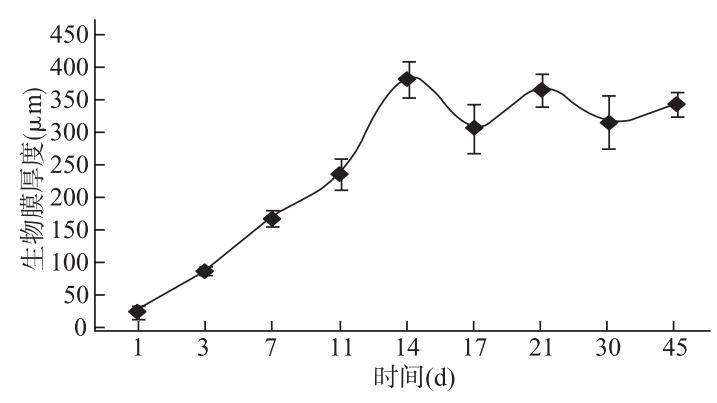

图 5 弹性填料上生物膜厚度的变化

Fig.5 Changes of biofilm thickness on elastic packing

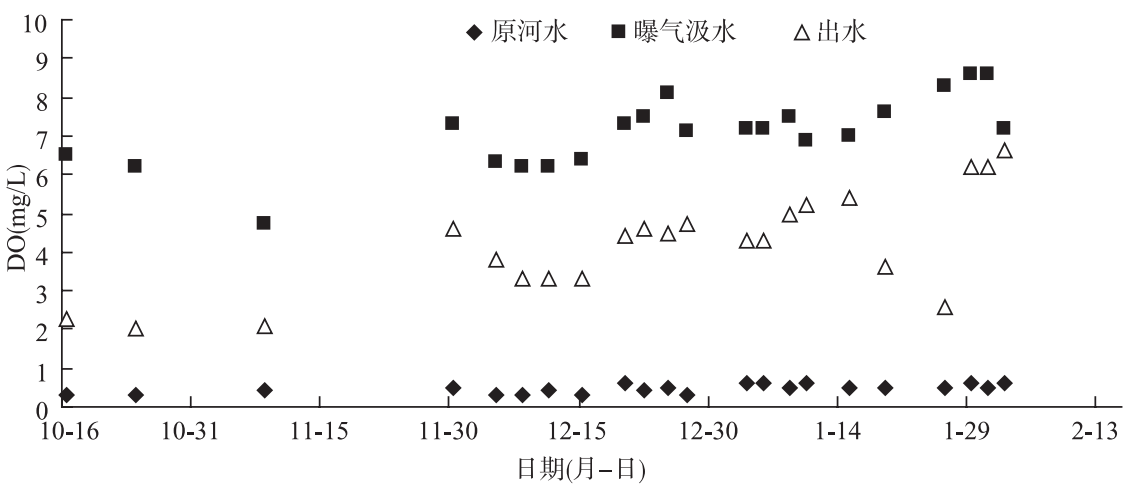

图 6 系统 DO 浓度变化

Fig.6 Changes of dissolved oxygen concentrations in the treatment system

\section{4 氮的去除与转化}

生态浮床系统中, 水体中的氮部分被植物和微生物直接吸收, 还通过微生物的硝化、反硝化作用将 其从水体中去除, 最后通过植物的收割使氮最终从系统中去除. 在本模型实验中, 系统进、出水中各种形 态氮组成及变化 (表 2)说明, 进水中 $\mathrm{NH}_{4}{ }^{+}-\mathrm{N}$ 占大部分, 平均为 $\mathrm{TN}$ 含量的 $84.8 \%$, 最高为 $96.2 \%$. 出水 $\mathrm{TN}$ 和 $\mathrm{NH}_{4}{ }^{+}-\mathrm{N}$ 浓度显著降低, 系统出水 $\mathrm{TN}$ 和 $\mathrm{NH}_{4}{ }^{+}-\mathrm{N}$ 平均浓度分别为 $5.39 \mathrm{mg} / \mathrm{L}$ 和 $1.23 \mathrm{mg} / \mathrm{L}, \mathrm{TN}$ 去除率为 $61.0 \%-90.1 \%$ (平均去除率为 $81.1 \%$ ), $\mathrm{NH}_{4}{ }^{+}-\mathrm{N}$ 的平均去除率为 $91.3 \%$. 
表 2 进、出水中不同形态氮浓度比较

Tab.2 Comparisons between inflow and outflow on different forms of nitrogen

\begin{tabular}{ccc}
\hline 指标 & 进水浓度 $(\mathrm{mg} / \mathrm{L})$ & 出水浓度 $(\mathrm{mg} / \mathrm{L})$ \\
\hline $\mathrm{NH}_{4}{ }^{+}-\mathrm{N}$ & $29.67 \pm 7.79$ & $2.59 \pm 2.14$ \\
$\mathrm{NO}_{3}{ }^{-}-\mathrm{N}$ & $0.42 \pm 0.25$ & $2.46 \pm 1.40$ \\
$\mathrm{NO}_{2}{ }^{-}-\mathrm{N}$ & $0.01 \pm 0.01$ & $0.13 \pm 0.11$ \\
Org-N & $4.90 \pm 6.31$ & $1.45 \pm 1.99$ \\
$\mathrm{TN}$ & $35.00 \pm 11.81$ & $6.62 \pm 3.10$ \\
\hline
\end{tabular}

微曝气生态浮床系统对 $\mathrm{TN}$ 和 $\mathrm{NH}_{4}{ }^{+}-\mathrm{N}$ 的去除率较高, 并且在进水水质不断变化的情况下去除效果比 较稳定, 但会有 $\mathrm{NO}_{3}{ }^{-}-\mathrm{N}$ 积累, 出水 $\mathrm{NO}_{3}{ }^{-}-\mathrm{N}$ 平均浓度为 $2.46 \mathrm{mg} / \mathrm{L}$, 而进水的 $\mathrm{NO}_{3}{ }^{-}-\mathrm{N}$ 平均浓度仅为 $0.42 \mathrm{mg} / \mathrm{L}$. 已有研究表明, 湿地对 $\mathrm{NO}_{3}{ }^{-}-\mathrm{N}$ 具有较高的去除率 ${ }^{[15-16]}$, 但在植物浮床系统中会产生 $\mathrm{NO}_{3}{ }^{-}-\mathrm{N}$ 积 累 ${ }^{[17]}$; 在本系统中也存在 $\mathrm{NO}_{3}{ }^{-}-\mathrm{N}$ 积累的现象, 说明系统中硝化作用高于反硝化作用.

\section{5 磷的去除}

浮床系统对磷的去除途径主要包括基质的过滤吸附、化学沉淀作用、植物的吸收、微生物的合成代 谢等途径. 本模型实验期间, 大清河河口原水中 $\mathrm{TP}$ 浓度在 $0.66-2.09 \mathrm{mg} / \mathrm{L}$ 之间, $\mathrm{PO}_{4}{ }^{3-}-\mathrm{P}$ 的平均浓度为 $0.49 \mathrm{mg} / \mathrm{L}$; 系统出水 $\mathrm{TP}$ 和 $\mathrm{PO}_{4}{ }^{3-}-\mathrm{P}$ 的平均浓度分别为 $0.32 \mathrm{mg} / \mathrm{L} 、 0.04 \mathrm{mg} / \mathrm{L}$; 系统 $\mathrm{TP}$ 的平均去除率为 $71.33 \%, \mathrm{PO}_{4}{ }^{3-}-\mathrm{P}$ 的平均去除率为 $91.4 \%$ (图 7).
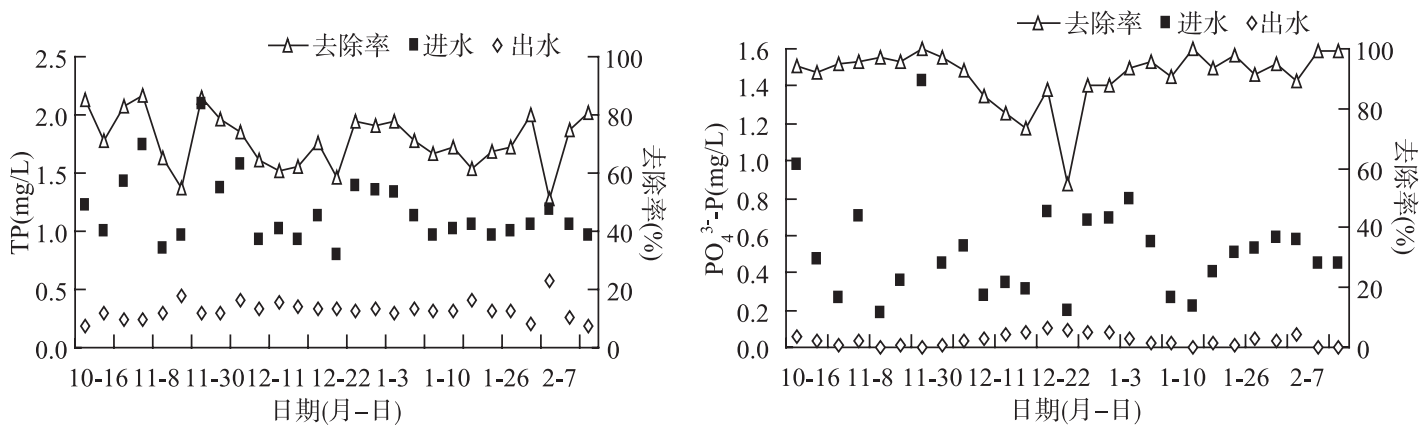

图 7 试验期间 TP、 $\mathrm{PO}_{4}{ }^{3-}-\mathrm{P}$ 的去除效果

Fig.7 The degradation effects of TP and $\mathrm{PO}_{4}{ }^{3-}-\mathrm{P}$ during experiment

\section{6 $\mathrm{COD}_{\mathrm{cr}}$ 的降解}

进水中不溶性的有机物通过基质和漂浮植物的吸附、过滤等物理作用被截留下来, 并且在微生 物的作用下进一步分解, 溶解性的有机物在经过生物膜表面和漂浮植物根系时被吸附然后被微生物 利用 ${ }^{[18]}$.

2006 年 10 月到 11 月, 进、出水 $\mathrm{COD}_{\mathrm{Cr}}$ 平均值分别为 $164.14 \mathrm{mg} / \mathrm{L} 、 31.97 \mathrm{mg} / \mathrm{L}, \mathrm{COD}_{\mathrm{Cr}}$ 去除率平均为 $80.6 \%$; 而 2006 年 12 月至 2007 年 2 月, 进、出水平均值分别为 $130.32 \mathrm{mg} / \mathrm{L}$ 和 $55.96 \mathrm{mg} / \mathrm{L}, \mathrm{COD}_{\mathrm{Cr}}$ 去除率 相对较低, 平均为 $56.6 \%$ (图 8). 整个试验阶段, 出水 $\mathrm{COD}_{\mathrm{Cr}}$ 平均值为 $49.74 \mathrm{mg} / \mathrm{L}$. 昆明地区在 12 月到翌 年的 2 月期间气温相对偏低, 漂浮植物和微生物对有机物的吸附分解作用可能受到一定的影响.

\section{7 主要污染物去除速率常数的比较}

$\mathrm{TN} 、 \mathrm{NH}_{4}{ }^{+}-\mathrm{N} 、 \mathrm{TP}$ 和 $\mathrm{COD}_{\mathrm{Cr}}$ 的去除速率常数 $K$ 可以从一级动力学方程中得到:

$$
C_{i}=C_{0} \mathrm{e}^{-K A / Q}
$$

式中: $C_{i}$ 为出水污染物浓度 $(\mathrm{mg} / \mathrm{L}) ; C_{0}$ 为进水污染物浓度 $(\mathrm{mg} / \mathrm{L}) ; A$ 为浮床表面积 $\left(\mathrm{m}^{2}\right) ; Q$ 为日流量 $\left(\mathrm{m}^{3} / \mathrm{d}\right) ; K$ 
为去除速率常数 $(\mathrm{m} / \mathrm{d})$.

本模型实验中, 微曝气生态浮床系统 $\mathrm{TN} 、 \mathrm{NH}_{4}{ }^{+}-\mathrm{N} 、 \mathrm{TP}$ 和 $\mathrm{COD}_{\mathrm{Cr}}$ 的去除速率常数 $K$ 见表 3.

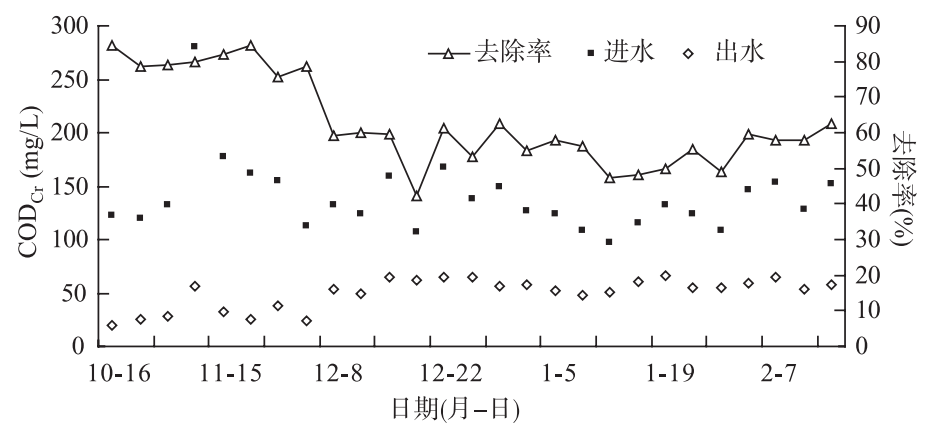

图 8 试验期间 $\mathrm{COD}_{\mathrm{Cr}}$ 的去除效果

Fig.8 Removal efficiency of $\mathrm{COD}_{\mathrm{Cr}}$ during experiment

表 3 污染物去除速率常数

Tab.3 Coefficient of contaminants removal rates

\begin{tabular}{cccc}
\hline 指标 & $\begin{array}{c}\text { 进水浓度 } \\
(\mathrm{mg} / \mathrm{L})\end{array}$ & $\begin{array}{c}\text { 出水浓度 } \\
(\mathrm{mg} / \mathrm{L})\end{array}$ & $\begin{array}{c}\text { 去除速率常数 } K \\
(\mathrm{~m} / \mathrm{d})\end{array}$ \\
\hline $\mathrm{TN}$ & $35.00 \pm 11.81$ & $6.62 \pm 3.10$ & $2.55 \pm 0.51$ \\
$\mathrm{NH}_{4}{ }^{+}-\mathrm{N}$ & $29.67 \pm 7.79$ & $2.59 \pm 2.14$ & $3.93 \pm 0.94$ \\
$\mathrm{TP}$ & $1.17 \pm 0.29$ & $0.32 \pm 0.08$ & $1.95 \pm 0.53$ \\
$\mathrm{COD}_{\mathrm{Cr}}$ & $139.09 \pm 34.89$ & $49.74 \pm 14.55$ & $1.59 \pm 0.59$ \\
\hline
\end{tabular}

\section{3 讨论与结论}

严以新等利用常规的生态浮床系统净化污染河水时, $\mathrm{TN}$ 和 $\mathrm{NH}_{4}-\mathrm{N}$ 的去除速率常数都为 $0.13 \mathrm{~m} / \mathrm{d}^{[19]}$; 抚仙湖窑泥沟构筑湿地净化人湖污染河水时 $\mathrm{NH}_{4}{ }^{+}-\mathrm{N}$ 的去除速率常数为 $0.34 \mathrm{~m} / \mathrm{d}^{[20]}$. 微曝气生态浮床净化 人湖河口污染河水模型实验中, $\mathrm{TN} 、 \mathrm{NH}_{4}{ }^{+}-\mathrm{N}$ 和 $\mathrm{COD}_{\mathrm{Cr}}$ 的去除速率常数平均分别为 $2.55 \mathrm{~m} / \mathrm{d} 、 3.93 \mathrm{~m} / \mathrm{d}$ 、 $1.59 \mathrm{~m} / \mathrm{d}$. 微曝气生态浮床对于原位处理黑臭河水、去除 $\mathrm{NH}_{4}{ }^{+}-\mathrm{N}$ 和有机污染物是有效的.

在微曝气生态浮床系统中污染物去除率较高, 将植物浮床技术与接触氧化相结合, 提高了水面利用 率(立体空间)和净化效率, 例如微曝气生态浮床选用的弹性立体填料比表面面积为 $250 \mathrm{~m}^{2} / \mathrm{m}^{3}$, 这充分利 用了水体的空间; 另一方面, 低压微量曝气系统提供的有氧环境是条件保障, 微曝气生态浮床布设微曝 气装置, 在模型底部进行曝气，使得整个系统中的 DO浓度提高, 模型出水的 DO平均值达到了 $4.18 \mathrm{mg} / \mathrm{L}$, 有利于好氧异养微生物的生长而形成生物膜.

微曝气生态浮床净化系统采用了可变换组合的结构方式, 整体由漂浮载体结构单元构成, 可根据具 体环境条件将其自由组合; 浮床下端悬挂弹性立体填料, 将其自由垂下，可随水流自由摆动; 浮床整体 可随水位变化而起伏. 另外, 微曝气生态浮床采用了不锈钢的漂浮载体框架, 单元结构牢固, 对外界冲 击具有一定的抗性, 不易损坏散架, 使用寿命长. 因此, 微曝气生态浮床可适用于流水环境规模化使用.

\section{4 参考文献}

[1] Lazarova V, Manem J. An innovative process for waste water treatment: the circulating floating bed reactor. Water Science and Technology, 1996, 34(9): 89-99.

[2] Sooknah RD, Wilkie AC. Nutrient removal by floating aquatic macriophyte cultured in anaerobical digested flushed manure wastewater. Ecological Engineering, 2004, 22: 27-42. 
[3] Aoi T, Hayashi T. Nutrient removal by water lettuce(Pistia stratiotes). Water Science and Technology, 1996, 34(7-8): 407-412.

[4] Reddy KR, Smith WH. Aquatic plants for water treatment and resource recovery. Orlando, FL: Magnolia Publishing Inc., 1987.

[5] Hamersley RM, Howes LB, White SD et al. Nitrogen balance and cycling in an ecologically engineered septage treatment system. Ecological Engineering, 2001, 18: 61-75.

[6] 李英杰, 年跃刚, 胡社荣等. 生态浮床对河口水质的净化效果. 中国给水排水, 2008, 24(11): 60-63.

[7] 方云英, 杨肖娥, 常会庆等. 利用水生植物原位修复污染水体. 应用生态学报, 2008, 19(2): 407-412.

[8] Kivaisi AK. The potential for constructed wetlands for wastewater treatment and reuse in developing countries: a review. Ecological Engineering, 2001, 16(3): 545-560.

[9] Suan BP, John MT. The role of plants in ecologically engineered wastewater treatment systems. Ecological Engineering, 1996, 6(1): 137-148.

[10] 李宝林. 凤眼莲净化水质的利用及其所诱发的环境问题. 环境保护, 1994, (4): 32-33.

[11] 李先宁, 宋海亮, 朱光灿等. 组合型浮床生态系统的构建及其改善湖泊水源地水质的效果. 湖泊科学, 2007, 19(4): 367-372.

[12] Lianpeng S, Yang L, Hui J. Nitrogen removal from polluted river by enhanced floating bed grown canna. Ecological Engineering, 2009, 35: 135-140.

[13] 国家环境保护总局. 水和废水监测分析方法(第四版). 北京: 中国环境科学出版社, 2002.

[14] 刘 雨, 赵庆良, 郑兴灿. 生物膜法污水处理技术. 北京: 中国建筑工业出版社, 2000.

[15] James FR, Alex JH, Craig DM. Nitrate removal from a drinking water supply with large free-surface constructed wetlands prior to groundwater recharge. Ecological Engineering, 2000, 14: 33-47.

[16] Matheson FE, Nguyen ML, Cooper $\mathrm{AB}$ et al. Fate of ${ }^{15} \mathrm{~N}$-nitrate in unplanted/planted and harvested riparian wetland soil microcosms. Ecological Engineering, 2002, 19: 249-264.

[17] 周小平，王建国，薛利红等. 浮床植物系统对富营养化水体中氮磷净化特征的初步研究. 应用生态学报，2005，16(11): 2199-2203.

[18] 吴晓碟. 人工湿地废水处理机理. 环境科学, 1995, 16(3): 83-86.

[19] 严以新, 操家顺, 李欲如. 冬-春季节浮床技术净化重污染河水的动态试验研究. 河海大学学报(自然科学版), 2006, 34(2): 119-122.

[20] 陈源高, 李文朝, 李荫玺等. 云南抚仙湖窑泥沟复合湿地的除氮效果. 湖泊科学, 2004, 16(4): 331-336. 